\title{
The transforming object of the veterinarian's clinical gaze
}

Kalevi Paldanius, Savonia-ammattikorkeakoulu, Iisalmen yksikkö, Haukisaarentie 2, 74130 Iisalmi, kalevi.paldanius@savonia-amk.fi

Although veterinary profession's function in society is very important there are relatively a few scientific studies about veterinary profession or how veterinarians' experience their work. In the field of study of work approaches based in activity theory (AT), has been held during last 15 years as a promising theoretical and practical tool. As such there is no unified definition of activity theory. One of the central concepts in AT is the notion of object in understanding and explaining human activity. Idea is that when we understand the object of activity we have found the key to understand activity system. Human activity is seen multidimensional system or structure. When applying AT in research important is how the subject interprets and approaches the problem space of her/his activity system. In this article I will focus on how municipal veterinarian in mixed practice experiences her/his work, animals and clients. I use activity theoretical notions to interpret the results.

The empirical material was collected by means of participant observation and interviews of two veterinarians - man and woman - in Eastern Finland during the time period June 2006 - October 2007. Observation time was altogether 3.5 working weeks, including approximately 120 - 130 consultations with clients in consulting rooms and in the farms. The analyses of the notes and interviews were made by theory driven content analysis. For analytical purposes I formed a typical case of two veterinarians whose work I observed. I refer to the case by an acronym "the Vet".

The activity of veterinarian is described as a continuum preventive - curative/clinical - euthanasia. My interpretation is that for the veterinarian animals are the object of clinical gaze in the realm of socio-economic organisation. By clinical gaze is meant a perceptual model than mere to seeing, more to functions like speaking, touching and knowing. But in this system the owners of animals form a critical factor. Client's way to take care of their animals defines whether they are favourite clients or not for the Vet and does the Vet feel that s/he is in the same boat or not with the client. The Vet feels that the owners of production animals understand her/his work better than owners of the pets. May be the idea of production defines animals as objects more clearly and thus easier to agree about activities than the idea about animal as a companion or friend?

Activity theoretical concepts apply well in analysing veterinarian's work in socio-economic system where animals are used to satisfy human needs. But the notion of animal as object of veterinarian's clinical gaze seems not to be enough in defining the special nature of veterinary work. In order to understand more fully the social dimension of activity of veterinarian, it is important to study how clients' experience veterinarians and their work.

Key words: veterinarian work, the object of activity, animal-human relations 


\section{Introduction}

Among the health professions veterinarians form a special expert group, who are defined as gatekeepers of human health (Hendrix et al. 2005, Pappainoanou 2004) and as mediators between human and animal world (Swabe 2005). According to these definitions veterinary professions function in society is very important but there is relatively a few research about veterinarians as a profession and their work. Odendaal (1998) has written an article where he stresses that in order to understand human side of veterinary practice it should be analyzed as a social system. Pillay \& Crindle (2005) studied novice and experts veterinarians using ultrasound technology when making diagnosis. They conceptualized professional expertise in the frame of activity theory constituting socio-cultural dispositions, strategies, tools and artefacts of a profession. Their findings showed the complexity of professional expertise particularly when individuals has to use sophisticated tools.

Professional ethics function as a regulating tool for tasks and also they define how the object of activity is seen. The ethical basis of veterinarian's work forms the respect of nature and life and they have to work for the benefit of animals without discriminating them on the basis of economical value or productivity. For the client a veterinarian has to present scientifically possible care alternatives. (Anon 2002)

In the field of study of work activity theoretical approaches has been held last years as a promising theoretical and practical tool. Although there is no unified definition of activity theory (Holzman 2006) notions of agency and of object (Barab \& Plucker 2002, Bedny \& Harris 2005, Kaptelinin 2005, Leontiev 1977) are hold central in understanding and explaining human activity. In this article I will focus on how veterinarians experience their work, animals and clients applying activity theoretical way of thinking to interpret the results.

There are approximately 1800 veterinarians in Finland of which about 400 works as municipal veterinarians (http://www.sell.fi/Pages/english.htm). In Finland municipal veterinarians work seemingly alone. From the activity theoretical perspective working alone doesn't mean that work is determined by individual, but social and cultural practices, tools, values etc. determine the work (Kaptelinin 2005). Municipal veterinarians represent also the traditional group of veterinarians working in countryside in mixed practice. By mixed practice is meant that a veterinarian treats livestock animals as well other animals like pets, horses etc.

Veterinarians take care of animals' well-being, treatment of illnesses and preventive activities as well as they euthanize animals - and not only hopelessly sick animals. From activity perspective we could ask: to what kind of activity animals are the key and what kind of object animals are? As living creatures they are neither artefacts nor humans but how they are constructed in daily practice (Engeström \& Blacker 2005) will help to understand the work of veterinarians.

\section{Data and methods}

The empirical material was collected by means of participant observation and interviews of two veterinarians - man and woman - in Eastern Finland during the time period June 2006 - October 2007. Observation time was altogether 3.5 working weeks, including approximately 120 - 130 consultations with clients in consulting rooms and in farms.

I started the analyses of the notes and interviews by using expressions or notes which repeated themselves in material as a key concept and draw mind maps around them about things which associated to them. For example when I arrived first time to the consulting room, the phone ringed and interrupted my discussion with the veterinarian over twenty times. So I used phone as a central concept and draw associations from observations around it like: time reservation, first contact to client, the first working hour, not long discussions. Or car: "trips”, necessary, driving, longer distances, good moments. Or cow barn: veterinarian's working space, easy, difficult, modern, cow's hell. Client: favourite, unfavoured, pet owner, cattle regard, demanding etc. 
I have formed a typical case of two veterinarians whose work I observed. In the text I refer to the case by the acronym "The Vet" and use pronoun s/he regardless of whether the agent is she or he.

\section{Results}

The sequence of the normal working day of the Vet starts by the phone hour. After the phone hour the Vet might have consultations at her/his clinic (see figure 1). Clients bring their pets or other animals like horses to the clinic. The tasks with the animals are mostly routines - so called first line practice like vaccinations against infections, neutering cats and dogs or horses' leg problems and rasping the horses' teeth or euthanizing a pet.

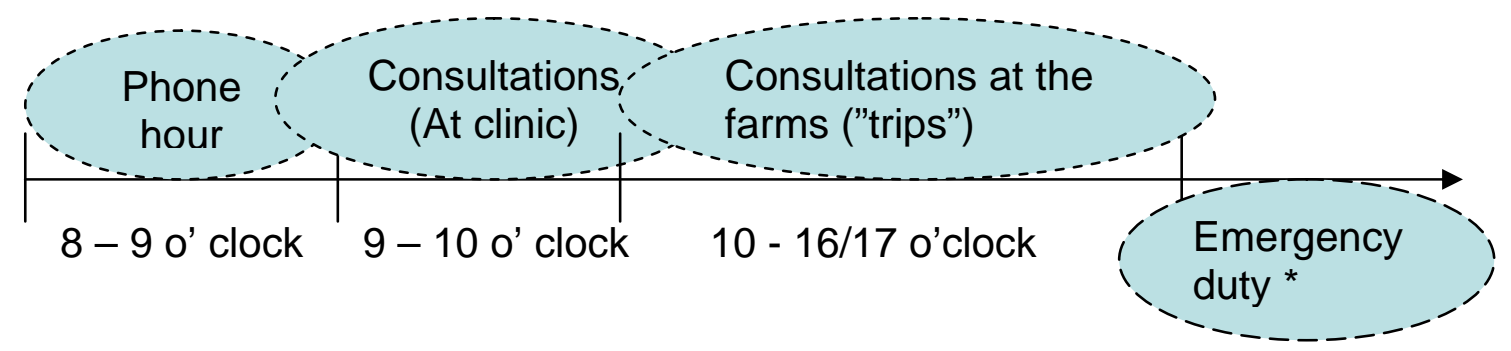

Figure 1 Sequence of the normal working day of the Vet

* Frequency of the emergency duty depends on how many municipalities and veterinarians belongs to the catchments' area of on call

Consultation at the clinic lasts from 1 hour to 1.5 hour. After that s/he starts "the trips" around countryside, from farm to farm, which are family-run, mostly dairy farms. According the Vet, the average amount of the "trips" is one hundred per month per veterinarian in Finland. Driving from the farm to farm represents to the Vet "the traditional go still", which might be one reason to why s/he has chosen "this job"? Every time before the Vet enters in the cow barn s/he has to wear on overalls and the boots because of contagious diseases. So s/he expresses the nature of her/his work and a change in it a little bit ironically: "Once, before there were no discussions about contagious diseases, the veterinarian's work was car driving and nowadays it is car driving and changing the clothes.”

At the cow barn or stall the Vet makes observations about the general appearance of an animal and makes questions to the owner. The importance of the client's "cattle regard" can be seen in the situations when there is replacement in the farm and the Vet arrives there. It might be that the worker "don't know what kind of the cow (normally) is", which makes it difficult to differentiate between animal's normal behaviour and behaviour which is due the illness.

But sometimes the owner's mere presence in the treatment situation might feel disturbing for the Vet and at least when the owner brings up new problematic cases, which has not been mentioned and discussed during phone interaction.

S/he also makes clinical examinations like listens by stethoscope, palpates, and makes rectal examination. Sometimes $\mathrm{s} / \mathrm{he}$ needs to take samples. This way s/he testes the hypothesis made in phone and makes the diagnosis sure. Treatment is normally medicament. S/he feels sometimes that the care recommendations are "that the alternatives are so that in the first place you use penicillin, secondarily penicillin and third alternative is penicillin...you take milk samples and you ponder what to use in this (case) and then you get it - let's put penicillin! Sometimes I feel that has the (veterinary) education been worthwhile of that."

The law defines what medicines are allowed to use and the spectrum of medicaments is small so s/he can cure $90 \%$ of illnesses by the medicines s/he has in her medicine bag. I have summarized the structure of Vet's clinical activity in figure two (next page). 

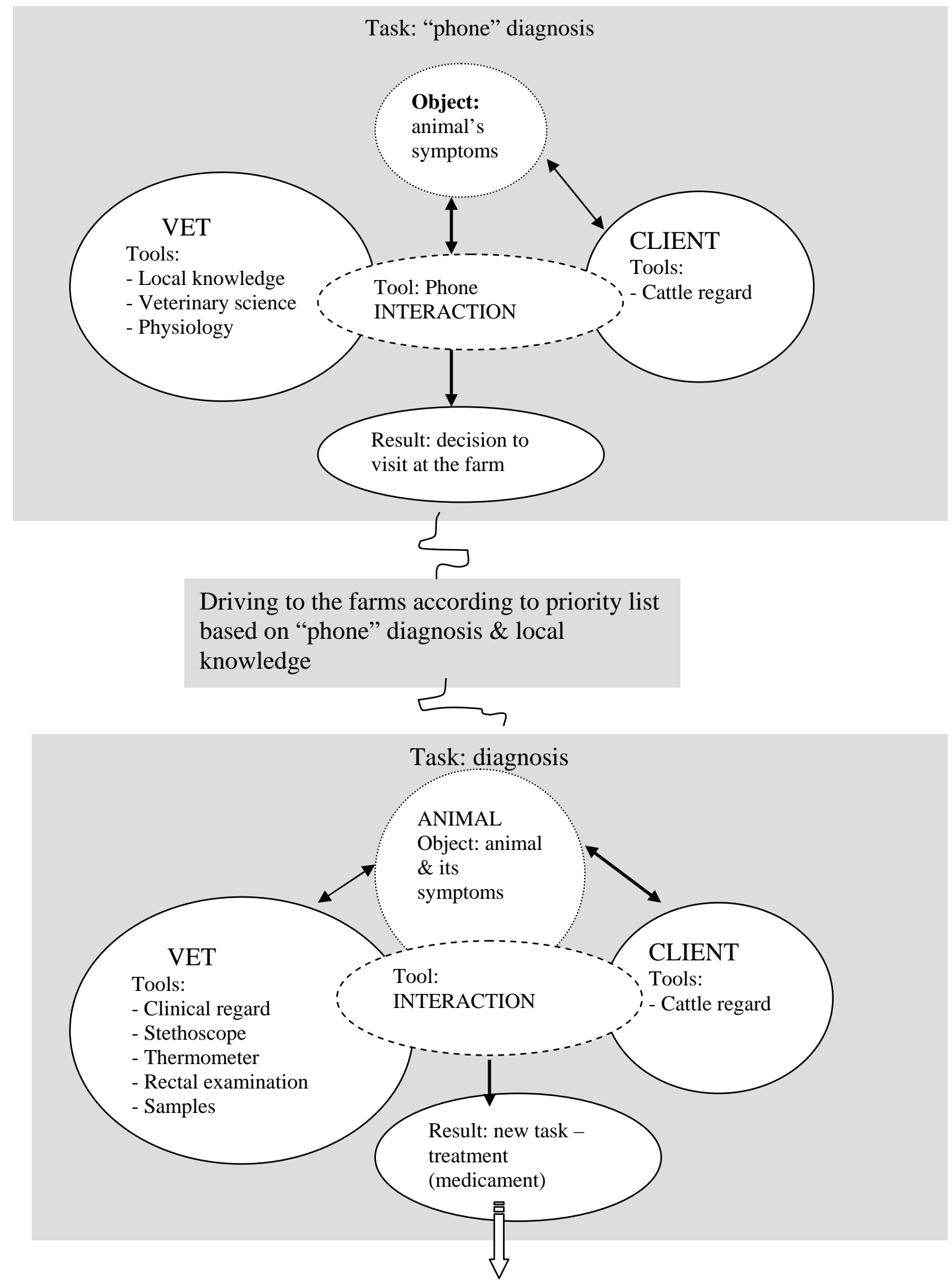

Result: healed animal 
The Vet sees that during last 5 - 10 years her/his work has changed and is changing from ambulatory work more towards preventive work. In practice it means that s/he doesn't only treat the sick animal but tries to found management factors which might have influence on the problems at the farm, like milk fever or fertility problems. Behind these might be e.g. shortage in feeding, hygiene or ventilation problems of cow barn. In Finland there have been projects where the health care plans are made for the farms and the costs are covered mostly by the project. The idea behind the subvention of health care programs is to motivate and teach farmers to do healthcare plans and work.

The central tool in preventive work is health care plan. From the perspective of the Vet to offer the health care plan just for the plan is embarrassing. When the initiative to make a health care plan comes from the farmer, the Vet feels that it is nice to do those plans. The better educated farmers understand the meaning of the preventive work but either they don't have time to do it or they don't find preventive work worthwhile because they find the return is acceptable already.

Killing the animal, or as veterinarian's like to say, put it down, is a task which differentiates veterinary work most clearly from the work of human physicians. Euthanasia is a normal part of veterinary practice. During my observation weeks the Vet had to kill two horses and one dog.

Normally it is a client's decision whether the animal is putted down or not. Exceptions are the cases when the law against the cruelty to animals is broken, when the Vet's duty is to interfere and make for example an order to kill the animal. If s/he is not sure about right decision s/he calls to the other expert and discusses with him before decision. Behind the cruelty to animals are the owner's social and economical troubles connected to alcoholic or mental health problems, but the Vet's task is not to estimate human's sufferings.

The law helps to make the limit between animal owners' and veterinarians' authority clearer and justifies the Vet's actions but sometimes s/he has to put down a healthy animal and then there is no law which helps you to make a decision.

Whether putting the animal down feels emotionally painful or not, depends on the Vet's emotional relationship to an animal. The animals are owned by other people and normally the Vet doesn't have emotional relationship to them. So putting down the animal is normally not painful. But the Vet has her own animal species preferences and when the animal represents liked species it might feel painful: "For some reasons putting down the cow is difficult, although there is not special emotional bonds." In euthanasia the object of activity is the life of an animal and it is motivated by putting an end to animal's suffering. The result is a dead animal.

When delivering professional services the problem generally is that the client is not always right. In the case of the Vet the client is always right in the sense that the owner of the animal makes the final decision about what to do, except in cases of cruelty to animals. The clients seem to play a crucial role in veterinarians work also. In the table one is an overview about how the Vet classifies her/his clients according to animals owned and whether they are favourite or unfavoured clients.

Table1. Clients from the perspective of the Vet's work

$$
\text { Production animal owners Owners of the pets/ hobby }
$$

Favourite clients Take good care of their animals: Take good care of their animals

"We are in the same boat" "More the care of the client than

Understand the activities of the the animal"

Vet

Unfavoured clients Bad care of the animals Bad care of the animals/

"Better knower"

There are - of course - clients whom the Vet doesn't like as persons. In these cases it is sake of honour for the Vet that those clients do not know about this personal disliking. More important is how the Vet categorizes clients according to how they take care of their animals. But despite of the tensions the clients arouse, they and the visits to the farms are "the salt of the work" for the Vet.

The Vet sees her/his profession a special kind because of its particular relation to the clients. The relationship forms intimate because the Vet goes to the clients' homes many times during years and s/he sees families in the situations which may be difficult and stressful. 


\section{Discussion}

In activity theory human activity is understood as a system or structure consisting different elements. Between the elements there might be contradictions which cause disturbances in work processes (Bedny \& Karkowski 2004, Engeström 2000). I have summarized the structure of the activity of veterinarian in mixed practice by using the general elements of activity: goal, task, tool and object. In the last row is mentioned contradictions associated in each activity by the Vet.

Table 2. The structure of veterinarian's activity

\begin{tabular}{|c|c|c|c|}
\hline \multicolumn{4}{|c|}{ Subject: Veterinarian } \\
\hline & Preventive & Curative & Euthanasia \\
\hline Goal & $\begin{array}{l}\text { Animal's well-being \& } \\
\text { productivity }\end{array}$ & Healing the animal & $\begin{array}{l}\text { Finish animal's } \\
\text { suffering }\end{array}$ \\
\hline Tasks & $\begin{array}{l}\text { Making a health care } \\
\text { plan }\end{array}$ & Diagnosis \& Therapy & Putting animal in a sleep \\
\hline Tools & $\begin{array}{l}\text { Analyzing production } \\
\text { processes in the farm }\end{array}$ & $\begin{array}{l}\text { Medical instruments \& } \\
\text { Medicines }\end{array}$ & $\begin{array}{l}\text { Chemicals (poison) } \\
\text { (Gun) }\end{array}$ \\
\hline Object & $\begin{array}{l}\text { Animal's living } \\
\text { conditions }\end{array}$ & Animal’s symptoms & Animal’s life \\
\hline Contradictions & $\begin{array}{l}\text { Client's initiative vs. } \\
\text { Veterinarian's } \\
\text { initiative } \\
\text { Economy vs. animals } \\
\text { as living creature }\end{array}$ & $\begin{array}{l}\text { Production animal } \\
\text { owner vs. pet owner } \\
\text { Routines vs. } \\
\text { challenging tasks }\end{array}$ & $\begin{array}{l}\text { Killing vs. cure } \\
\text { Animal's suffering vs. } \\
\text { human's suffering }\end{array}$ \\
\hline & Client servic & e vs. professionalism & \\
\hline
\end{tabular}

From the table 2 can be seen that veterinarian's daily activity consist of complex set of goals, tasks, tools and transforming object. But whether the object is animal's living conditions, symptoms or its life it is always seen through the Vet's clinical gaze. This perceptual model to see, touch, know and speak about animal is the core of veterinary profession, which in turn forms the contradiction between client service and professionalism. The other contradictions can be interpreted as different variations of this basic contradiction.

During domestication, development of farming and livestock culture animals has become a form of property and integrated as objects into the socio-economic organisation (Ingold 2002, Seamer 1998, Ylimaunu 2002) in the realm of which veterinarians' activities are carried out. But as we have seen in this system the owners of animals form a critical factor. Client's way to take care of their animals defines whether they are favourite clients or not for the Vet and does the Vet feel that $\mathrm{s} / \mathrm{he}$ is in the same boat with the client. The Vet feels that the owners of production animals understand her/his work better than owners of the pets. May be the idea of production defines animals as objects more clearly and thus easier to agree about activities than the idea about animal as a companion or friend?

Activity theoretical concepts apply well in analysing veterinarian's work in socio-economic system where animals are used to satisfy human needs. The notion of object seems not to be enough in defining the special nature of veterinary work. In order to understand more fully the mediating role of veterinarian, the social dimension of the work - how clients see and experience veterinarian and her/his work - has to be analyzed also. 


\section{References}

Anon (2002) Eläinlääkäri - eläimen paras ystävä. Suomen Eläinlääkäriliitolta uudet eettiset ohjeet eläinlääkäreille. Suomen Eläinlääkärilehti, 108, (12) p. 735.

Barab, S.A. \& Plucker, J.A. (2002) Smart People or Smart Contexts? Cognition, Ability, and Talent Development in an Age of Situated Approaches to Knowing and Learning. Educational Psychologist (37),3, 165-182.

Bedny, G. Z. \& Harris, S.R. (2005) The Systemic-Structural Theory of Activity: Applications to the Study of Human Work. Mind, Culture, and Activity, (12), 2, 128-147.

Bedny, G.Z. \& Kakowski, W. (2004) Activity theory as a basis for the study of work. Ergonomics, 47 (2), 134 $-153$.

Engeström, Y. (2000) Activity theory as a framework for analyzing and redesigning work. Erconomics (43), 7, 960-974.

Engeström, Y. \& Blackler, F. (2005) On the Life of the Object. Organization 12 (3), 307 - 330.

Hendrix, C.M., McClelland, C.L., Thompson, I., Maccabe, A.T. \& Hendrix, C. R. (2005) An interprofessional role for veterinary medicine in human health promotion and disease prevention. Journal of interprofessional care. 19 (1), pp. 3 - 10.

Holzman, L. (2006) What Kind of Theory is Activity Theory? Introduction. Theory \& Psychology 16 (1), pp. 5 -11 .

Ingold, T. (2002) From Trust to Domination. An alternative history of human-animal relations. In A. Manning \& J. Serpell (ed.) Animals and Human Society. Changing perspectives. Routledge. New Yourk. pp. $1-22$.

Kaptelinin, V. (2005) The Object of Activity: Making Sense of the Sense-Maker. Mind, Culture, and Activity (12), $1,4-18$.

Leontiev, A.N. (1977) Toiminta, tietoisuus, persoonallisuus. Kansankulttuuri Oy. Kuopio.

Odendaal, J.S.J. (1998) The practicing veterinarian and animal welfare as a human endeavour. Applied Animal Behaviour Science (59), 85-91.

Pappainoanou, M. (2004) Veterinary medicine protecting and promoting the public's health and well-being. Preventive Veterinary Medicine. 62, pp. 153 - 163.

Pillay, H. \& McCrindle, A.R. (2005) Distributed and relative nature of professional expertise. Studies in Continuing Education (27), 1, pp. 67 - 88.

Seamer, J. H. (1998) Human stewardship and animal welfare. Applied Animal Behaviour Science (59), p.201205

Swabe, J. (2005) Veterinary dilemmas: ambiguity and ambivalence in human- animal interaction. In A. L. Podberscek, E.S. Paul, J. A. Serpell (ed.) Companion animals and Us. Exploring the relationships between people and pets. Cambridge University Press. Cambridge. p. $292-312$.

Ylimaunu, J. (2002) Elinkeinot ihmisen ja eläimen suhteen muokkaajina. In H. Ilomäki and O. Lauhakangas (ed.) Eläin ihmisen mielenmaisemassa. Suomalaisen kirjallisuuden seura. Helsinki. pp. 115 - 133.

Other references:

The Special Features of The Veterinary Profession in Finland http://www.sell.fi/Pages/english.htm(19.4.07) 